\title{
Functional Group Distribution of the Carrier Surface Influences Adhesion of Methanothermobacter thermautotrophicus
}

\author{
Masaki Umetsu (D, ${ }^{1,2}$ Takaaki Sunouchi, ${ }^{3}$ Yasuhiro Fukuda, ${ }^{1}$ Hideyuki Takahashi, ${ }^{3}$ \\ and Chika Tada $\mathbb{D}^{1}$ \\ ${ }^{1}$ Graduate School of Agricultural Science, Tohoku University, Miyagi 989-6711, Japan \\ ${ }^{2}$ Research Fellow of the Japan Society for the Promotion of Science (JSPS), Tokyo 102-0083, Japan \\ ${ }^{3}$ Graduate School of Environmental Studies, Tohoku University, Miyagi 980-8579, Japan \\ Correspondence should be addressed to Chika Tada; chika.tada.e1@tohoku.ac.jp
}

Received 8 October 2019; Accepted 8 January 2020; Published 23 January 2020

Academic Editor: Alla Nozhevnikova

Copyright ( 2020 Masaki Umetsu et al. This is an open access article distributed under the Creative Commons Attribution License, which permits unrestricted use, distribution, and reproduction in any medium, provided the original work is properly cited.

\begin{abstract}
Various support carriers are used for high-density retention of methanogenic archaea in anaerobic wastewater treatment systems. Although the physicochemical properties of carrier materials and microorganisms influence the adhesion of methanogenic archaea, details about the underlying mechanism remain poorly characterized. We applied seven types of chemical surface modifications to carbon felts to clarify the adhesion properties of Methanothermobacter thermautotrophicus, a representative thermophilic hydrogenotrophic methanogen. The relationship between carrier surface properties and methanogen adhesion was evaluated. $M$. thermautotrophicus adhesion was significantly increased up to 2.6 times in comparison with control on carbon felts treated with $\mathrm{NaOH}, \mathrm{HCl}, \mathrm{H}_{2} \mathrm{SO}_{4}$, or $\mathrm{Na}_{2} \mathrm{HPO}_{4}$. Treated carbon felts showed a lower water contact angle, but no correlation between the carrier surface contact angle and methanogen adhesion was observed. On the other hand, at the surface of the carrier that showed improved adhesion of methanogens, the ratio of $-\mathrm{COOH}:-\mathrm{OH}$ was $1: 0.65$. Such a ratio was not observed with treated carriers for which methanogen adhesion was not improved. Therefore, in the adhesion of M. thermautotrophicus, the functional group abundance was important as well as physical surface properties such as the hydrophobicity. Hydrogenotrophic methanogens are involved in active methanation during the startup of anaerobic digestion. Additionally, these methanogenic archaea function as methanogenic cathode catalysts. Therefore, anaerobic digestion performance will greatly improve by controlling the adhesion of hydrogenotrophic methanogens such as M. thermautotrophicus.
\end{abstract}

\section{Introduction}

Anaerobic digestion is considered a sustainable technology compared with aerobic processing, because it incurs minimal costs while producing beneficial end products (such as methane and digestive solution) [1]. As the growth of these methanogenic archaea is slower than that of microorganisms in other consortia, this step represents the rate-limiting reaction in methane production and, in particular, when starting up the reactor [2]. Therefore, having a high density of methanogenic archaea in a reactor is essential to ensure a highly efficient methane fermentation process.

A wide variety of materials (such as glass, pumice, and resins) has been studied as microbial support carriers to achieve high-density retention of the anaerobic consortium.
The adhesion of methanogenic archaea is particularly important, and some adhesion experiments using pure culture of the methanogens were performed. Verrier et al. [3] compared the quantity of adhesion of acetotrophic methanogens (Methanosarcina mazei and Methanosaeta concilii) and hydrogenotrophic methanogens (Methanobrevibacter arboriphilicus and Methanospirillum hungatei) for hydrophobic different carriers. The condition of the carrier surface that was easy to attach to varied according to the species of methanogens [3]. In addition, although both Methanosarcina barkeri and M. concilii are mesophilic acetotrophic methanogens, the cell surface properties and favorable carrier surface conditions were reported to be different [4]. However, the parameter influencing the adhesion of methanogens was not identified, because carriers of different materials and 
surface shape were compared by these experiments. In addition, the adhesion of thermophilic methanogens is not clear, because most of these studies focused on mesophilic acetotrophic methanogens. In anaerobic digestion, acetotrophic methanogens dominated during the stable phase, but hydrogenotrophic methanogen was reported to play an important role during the startup phase [5]. Therefore, by accumulating hydrogenotrophic methanogen on the carrier in the initial phase, it is thought that the startup period of methane fermentation can be shortened and stabilized.

Recently, it was reported that methanogenic archaea generated methane gas by exchanging electrons directly between specific bacteria [6]. The addition of electrically conductive carbon materials $[7,8]$ and minerals $[9,10]$ promotes this symbiosis. Accordingly, an electric conductive carrier could support a high-density of methanogenic archaea and significantly improve the performance of anaerobic digestion. Research on such electrochemical relations has advanced in recent years, with studies on methanation using methanogenic archaea as electrode catalysts $[11,12]$. In this reaction, methanogens are thought to receive electrons directly from the electrode and produce methane, highlighting the importance of understanding the adhesion of methanogens to electrode materials.

Methanothermobacter thermautotrophicus is a typical thermophilic hydrogenotrophic methanogen. M. thermautotrophicus strain $\Delta \mathrm{H}$ and Pelotomaculum thermopropionicum (a propionate oxidizing bacterium) live together and are connected through a conductive nanowire $[13,14]$. In addition, $M$. thermautotrophicus is more likely to be a promising cathode catalyst because $M$. thermautotrophicus is a dominant species on the high temperature methanogenic cathode $[12,15]$.

This study aimed to clarify the adhesion properties of $M$. thermautotrophicus to conductive materials. Carbon felt was used as the conductive material, and its surface was treated using various chemicals, followed by evaluation of potential change in the contact angle and functional group distribution. In addition, we attempted to clarify the surface properties that participated in the adhesion of methanogen by comparing the quantity of $M$. thermautotrophicus strain $\Delta \mathrm{H}$ that attached to each treated carrier.

\section{Materials and Methods}

2.1. Chemical Surface Treatment of Carbon Felt Carrier. Carbon felt (CARBORON ${ }^{\circledR}$ felt; Nippon Carbon Co., Ltd., Japan) prepared in a cylinder shape $(1 \mathrm{~cm}$ in diameter, $0.5 \mathrm{~cm}$ in thickness) was used as a support carrier. The following chemicals were applied to modify the felt surface: $\mathrm{KOH}, \mathrm{NaOH}, \mathrm{HCl}, \mathrm{HNO}_{3}, \mathrm{H}_{2} \mathrm{SO}_{4}, \mathrm{Na}_{2} \mathrm{SO}_{4}$, and $\mathrm{Na}_{2} \mathrm{HPO}_{4}$, while distilled water was used as the control. Different treatments were selected to compare acid treatments $(\mathrm{HCl}$, $\mathrm{HNO}_{3}$, and $\left.\mathrm{H}_{2} \mathrm{SO}_{4}\right)$ and basic treatments $(\mathrm{NaOH}$ and $\mathrm{KOH})$. We predicted that functional groups containing elements with a high affinity for carbon would show greater attachment to the support. Therefore, treatments containing sulfur $\left(\mathrm{H}_{2} \mathrm{SO}_{4}\right.$ and $\left.\mathrm{Na}_{2} \mathrm{SO}_{4}\right)$ and phosphorus $\left(\mathrm{Na}_{2} \mathrm{HPO}_{4}\right)$ with high affinity for carbon were performed.
For each treatment, the carbon felt was completely immersed in a $1.0 \mathrm{M}$ solution of each chemical by multiple vacuum degassing. Chemical surface modification was performed by $6 \mathrm{~h}$ of reflux at $100^{\circ} \mathrm{C}$ using a Findenser and hot stirrer. The support material used for the analysis of surface properties was washed using distilled water until the washing solution became neutral and was then dried in a drying furnace $\left(60^{\circ} \mathrm{C}\right.$ under atmospheric pressure and humidity). The support carrier used for the adhesion experiment was washed with purified water but without drying.

\subsection{Analysis of the Surface Properties of the Carbon Felt} Carrier. The water contact angle was measured using a contact angle meter (face CA-DS; Kyowa Interface Science Co., Ltd., Saitama, Japan). Fourier-transformed infrared (FT-IR) spectroscopy was used for the analysis of functional groups on the carbon felt material that had been altered by chemical surface modification. The chemically modified carbon felt was cut and mixed with $\mathrm{KBr}$ (Wako Pure Chemical Industries, Ltd., Osaka, Japan) at a $\mathrm{KBr}$ : carbon felt ratio of 400: $100 \mathrm{mg}$. The mixture was analyzed by FT-IR on a Frontier MIR/NIR spectrometer (PerkinElmer Japan Co., Ltd., Kanagawa, Japan).

2.3. Adhesion Experiment for M. thermautotrophicus Strain $\Delta H$. M. thermautotrophicus strain $\Delta \mathrm{H}$ (NBRC 100330) was obtained from the NITE Biological Resource Center (NBRC, Chiba, Japan). Culture medium was prepared by dissolving $0.14 \mathrm{~g} / \mathrm{L}$ of $\mathrm{KH}_{2} \mathrm{PO}_{4}, \quad 0.54 \mathrm{~g} / \mathrm{L}$ of $\mathrm{NH}_{4} \mathrm{Cl}, \quad 0.20 \mathrm{~g} / \mathrm{L}$ of $\mathrm{MgCl}_{2} \cdot 6 \mathrm{H}_{2} \mathrm{O}, 0.15 \mathrm{~g} / \mathrm{L}$ of $\mathrm{CaCl}_{2} \cdot 2 \mathrm{H}_{2} \mathrm{O}, 2.5 \mathrm{~g} / \mathrm{L}$ of $\mathrm{NaHCO}_{3}$, $0.20 \mathrm{~g} / \mathrm{L}$ of yeast extract (Difco, Detroit, MI, USA), $0.80 \mathrm{~g} / \mathrm{L}$ of sodium acetate, $0.1 \mathrm{mg} / \mathrm{L}$ of resazurin, and a trace element solution. Next, $5 \mathrm{~mL}$ aliquots of culture medium were transferred to $50 \mathrm{~mL}$ serum bottles and sterilized by autoclaving $\left(120^{\circ} \mathrm{C}\right.$ for $\left.20 \mathrm{~min}\right)$ after bubbling with nitrogen gas (99.999\%) for $2 \mathrm{~min}$ and then capping with butyl rubber stoppers. Filtered vitamin solution, $0.5 \mathrm{~g} / \mathrm{L}$ cysteine- $\mathrm{HCl}$, and $0.5 \mathrm{~g} / \mathrm{L} \mathrm{Na}_{2} \mathrm{~S} \cdot 9 \mathrm{H}_{2} \mathrm{O}$ were injected with a syringe through the rubber stopper, and $\mathrm{HCl}$ was added to adjust the $\mathrm{pH}$ to 7 . The trace element and vitamin solutions were referred to NBRC Medium 1067. The bottles were opened once to insert five treated carriers, bubbled with filtered nitrogen gas for $2 \mathrm{~min}$, and sealed immediately with a butyl rubber stopper.

A $5 \mathrm{~mL} M$. thermautotrophicus strain $\Delta \mathrm{H}$ culture aliquot was inoculated into the prepared vial using a syringe. Subsequently, a mixed gas was pumped such that the gas layer had $1.5 \mathrm{~atm}$ and $\mathrm{H}_{2}: \mathrm{CO}_{2}$ ratio of $80: 20$; stationary culturing was performed at $55^{\circ} \mathrm{C}$ for 21 days.

2.4. Scanning Electron Microscopy (SEM). After 21 days of culturing, the support carriers were taken out from the culture bottles. The samples were rinsed three times with sterile $0.9 \%(w / v) \mathrm{NaCl}$ solution to remove any residue. Cells adhered to the support carrier were fixed with $1.25 \%$ glutaraldehyde in $67 \mathrm{mM}$ phosphate-buffered saline ( $\mathrm{pH} 6.5$ ) at $4^{\circ} \mathrm{C}$ for $3 \mathrm{~h} \mathrm{[16].} \mathrm{After} \mathrm{dehydrating} \mathrm{stepwise} \mathrm{with} \mathrm{ethanol,} \mathrm{the}$ samples were dried with $t$-butyl alcohol and coated with platinum palladium. The specimen was then viewed by SEM (SU8000; Hitachi, Tokyo, Japan). 
2.5. DNA Extraction and Quantitative Real-Time Polymerase Chain Reaction (RT-PCR). RT-PCR targeting 16S rDNA of archaea was performed to compare the quantity of methanogenic archaea adhered to each treated carrier. After culturing, the carbon felt washed with $0.9 \% \mathrm{NaCl}$ and was crushed to extract DNA using the PowerSoil ${ }^{\circledR}$ DNA Isolation Kit (MO BIO Laboratories, Inc., Carlsbad, CA, USA) according to the manufacturer's instruction.

RT-PCR was performed using the Chromo $4^{\mathrm{TM}}$ and Opticon Monitor ${ }^{\mathrm{TM}}$ software (ver. 3.1; Bio-Rad Laboratories, Inc., Hercules CA, USA) and the Mighty Amp ${ }^{\circledR}$ system for RealTime (SYBRR Plus) (Takara Bio Inc., Shiga, Japan). According to the manufacturer's instructions, the reaction solution $(25 \mu \mathrm{L})$ was prepared by mixing $2 \mathrm{x}$ Mighty Amp for RealTime buffer (TB Green ${ }^{\mathrm{TM}}$ Plus, $\left.12.5 \mu \mathrm{L}\right)$, primers $1106 \mathrm{~F}\left(5^{\prime}\right.$ -TTWAGTCAGGCAACGAGC-3') and 1378R (5' ${ }^{\prime}$ TGTG CAAGGAGCAGGGAC-3'; $1 \mu \mathrm{L}$ each) [17], extracted DNA $(1 \mu \mathrm{L})$, and sterile Milli-Q water. The RT-PCR program comprised an initial denaturation step at $95^{\circ} \mathrm{C}$ for $10 \mathrm{~s}$, followed by 50 cycles of denaturation at $95^{\circ} \mathrm{C}$ for $10 \mathrm{~s}$, annealing at $57^{\circ} \mathrm{C}$ for $10 \mathrm{~s}$, and extension at $72^{\circ} \mathrm{C}$ for $6 \mathrm{~s}$ [18]. The statistical significance of differences between the carbon felts treated with purified water and chemicals was determined using the unpaired Student's $t$-test.

\section{Results}

3.1. Effect of Chemical Treatment on Contact Angle. The contact angle to purified water was measured to compare the surface hydrophobicity of the carbon felt material (Table 1). The contact angle of carbon felt treated with purified water (control) exhibited a high hydrophobicity of 136 $\pm 6.4^{\circ}$. All other chemical-treated carrier materials showed a tendency towards hydrophilicity; in particular, $\mathrm{KOH}-$, $\mathrm{HCl}$-, $\mathrm{HNO}_{3}^{-}$, and $\mathrm{H}_{2} \mathrm{SO}_{4}$-treated carriers exhibited significant hydrophilization (126-130 $)(p<0.05, t$-test). However, even the $\mathrm{H}_{2} \mathrm{SO}_{4}$-treated carrier that possessed the smallest contact angle $\left(126 \pm 3.1^{\circ}\right)$ was still within the hydrophobic surface category.

3.2. Effect of Chemical Treatment on Surface Functional Groups. FT-IR analysis was performed to investigate the changes in functional groups following surface treatment. Figure 1 presents the FT-IR spectra $\left(500-4000 \mathrm{~cm}^{-1}\right)$ of carbon felts treated with purified water or $\mathrm{NaOH}, \mathrm{HNO}_{3}$, and $\mathrm{H}_{2} \mathrm{SO}_{4}$. In all samples, bands around 1385, 1630, and $3435 \mathrm{~cm}^{-1}$ and bands from 2820 to $2920 \mathrm{~cm}^{-1}$ were seen.

Peaks at $1385 \mathrm{~cm}^{-1}$ and $1630 \mathrm{~cm}^{-1}$ matched those of expansion and contraction of the $-\mathrm{COOH}$ and $-\mathrm{C}=\mathrm{O}$ groups, respectively [19]. The peak at $2820-2920 \mathrm{~cm}^{-1}$ matched the peak of $-\mathrm{CH}$. The band at $3435 \mathrm{~cm}^{-1}$ matched the peak of expansion and contraction of $-\mathrm{OH}$ in the $\mathrm{COOH}$ functional group $[20,21]$. These findings indicated that the amount of $-\mathrm{COOH},-\mathrm{C}=\mathrm{O},-\mathrm{CH}$, and $-\mathrm{OH}$ functional groups changed following chemical treatment. This result was common to all eight types of chemical treatments performed in this experiment, and no characteristic change was observed except for peaks caused by these four functional groups.
TABLE 1: Water contact angle of carbon felts after chemical surface treatment.

\begin{tabular}{lc}
\hline & Contact angle (degree $)^{\mathrm{a}}$ \\
\hline Distilled water & $136 \pm 6.4$ \\
$\mathrm{NaOH}$ & $131 \pm 3.4$ \\
$\mathrm{KOH}$ & $129 \pm 3.0^{*}$ \\
$\mathrm{HCl}$ & $128 \pm 3.2^{*}$ \\
$\mathrm{HNO}_{3}$ & $130 \pm 3.0^{*}$ \\
$\mathrm{H}_{2} \mathrm{SO}_{4}$ & $126 \pm 3.1^{*}$ \\
$\mathrm{Na}_{2} \mathrm{SO}_{4}$ & $134 \pm 3.7$ \\
$\mathrm{Na}_{2} \mathrm{HPO}_{4}$ & $134 \pm 3.6$ \\
\hline
\end{tabular}

${ }^{\text {a The values are means } \pm \text { standard deviations }(n=16) .{ }^{*} \text { Indicates treatment }}$ effect is significant $(p<0.05)$ according to the $t$-test.

The intensity ratio of the functional groups on the treated carrier surface relative to the control is shown in Figure 2. In the $\mathrm{H}_{2} \mathrm{SO}_{4}$-treated carbon felt, characterized by the smallest contact angle, the hydrophilic groups $-\mathrm{COOH},-\mathrm{C}=\mathrm{O}$, and -OH increased by 5.55 times, 4.59 times, and 4.46 times, respectively, compared with those in the control surface. Both $\mathrm{Na}_{2} \mathrm{SO}_{4}$ and $\mathrm{Na}_{2} \mathrm{HPO}_{4}$ treatments exhibited almost identical contact angles as the control $\left(134^{\circ}\right)$, but the abundance of each functional group differed greatly. This observation demonstrated that the composition of the functional groups could differ in spite of the contact angle remaining the same. No significant difference was noted between the contact angle of $\mathrm{NaOH}$-treated felts and the control; however, the amount of hydrophilic functional groups $(-\mathrm{COOH}$, $-\mathrm{C}=\mathrm{O}$, and $-\mathrm{OH}$ ) was increased by approximately twofold. The quantity of hydrophilic groups showed almost no difference with respect to the control also following acid treatment with $\mathrm{HNO}_{3}$, whereas the hydrophobic $-\mathrm{CH}$ groups decreased to $1 / 10$.

3.3. Changes in Adhesion of Methanogenic Archaea following Chemical Treatment. After 21 days of culturing, $\mathrm{H}_{2}$ in the gas layer was completely converted to $\mathrm{CH}_{4}$ in all culture systems. The quantity of methanogenic archaea adhering to the carbon felts in different systems was compared by quantitative PCR. As shown in Figure 3, attachment was significantly higher in carbon felts treated with $\mathrm{NaOH}, \mathrm{HCl}, \mathrm{H}_{2} \mathrm{SO}_{4}$, and $\mathrm{Na}_{2} \mathrm{HPO}_{4}$ compared with the control $(p<0.05 ; t$-test). In contrast, no significant difference was noted between carriers treated with the other chemicals and the control.

SEM images in Figure 4 show the methanogens adhering to the chemical-treated carriers. Rod-shaped cells of $M$. thermautotrophicus were found attached to the felt fibers. As a result of having measured quantity of methanogen adhesion per unit area from SEM observation (data not shown), quantity of adhesion significantly increased with $\mathrm{NaOH}-, \mathrm{HCl}-$, $\mathrm{H}_{2} \mathrm{SO}_{4^{-}}$, and $\mathrm{Na}_{2} \mathrm{HPO}_{4}$-treated carriers in comparison with the control ( $p<0.05$; $t$-test). SEM evaluation of the changes in adhesion of methanogens in relation to chemical treatment confirmed the results obtained by RT-PCR (Figure 3). 


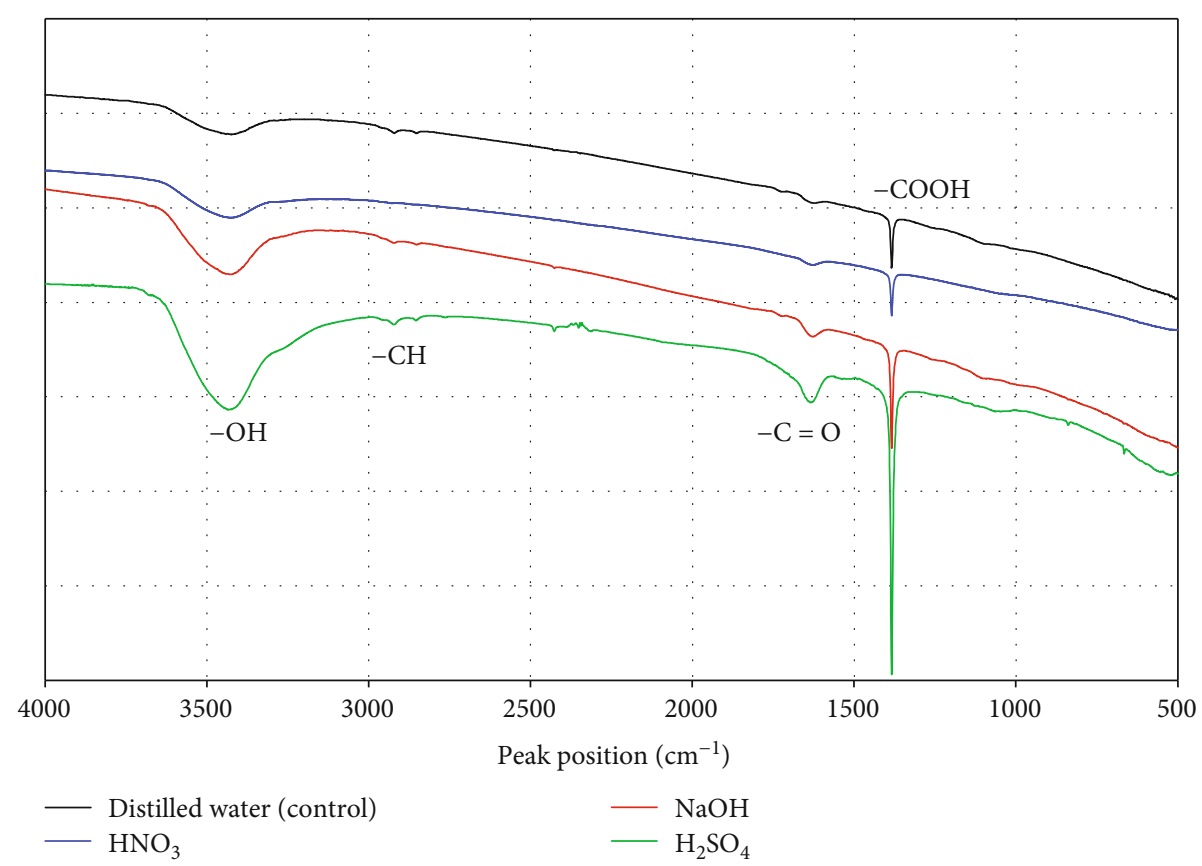

FIGURE 1: FT-IR spectra $\left(500-4000 \mathrm{~cm}^{-1}\right)$ of carbon felts subjected to chemical surface treatment.

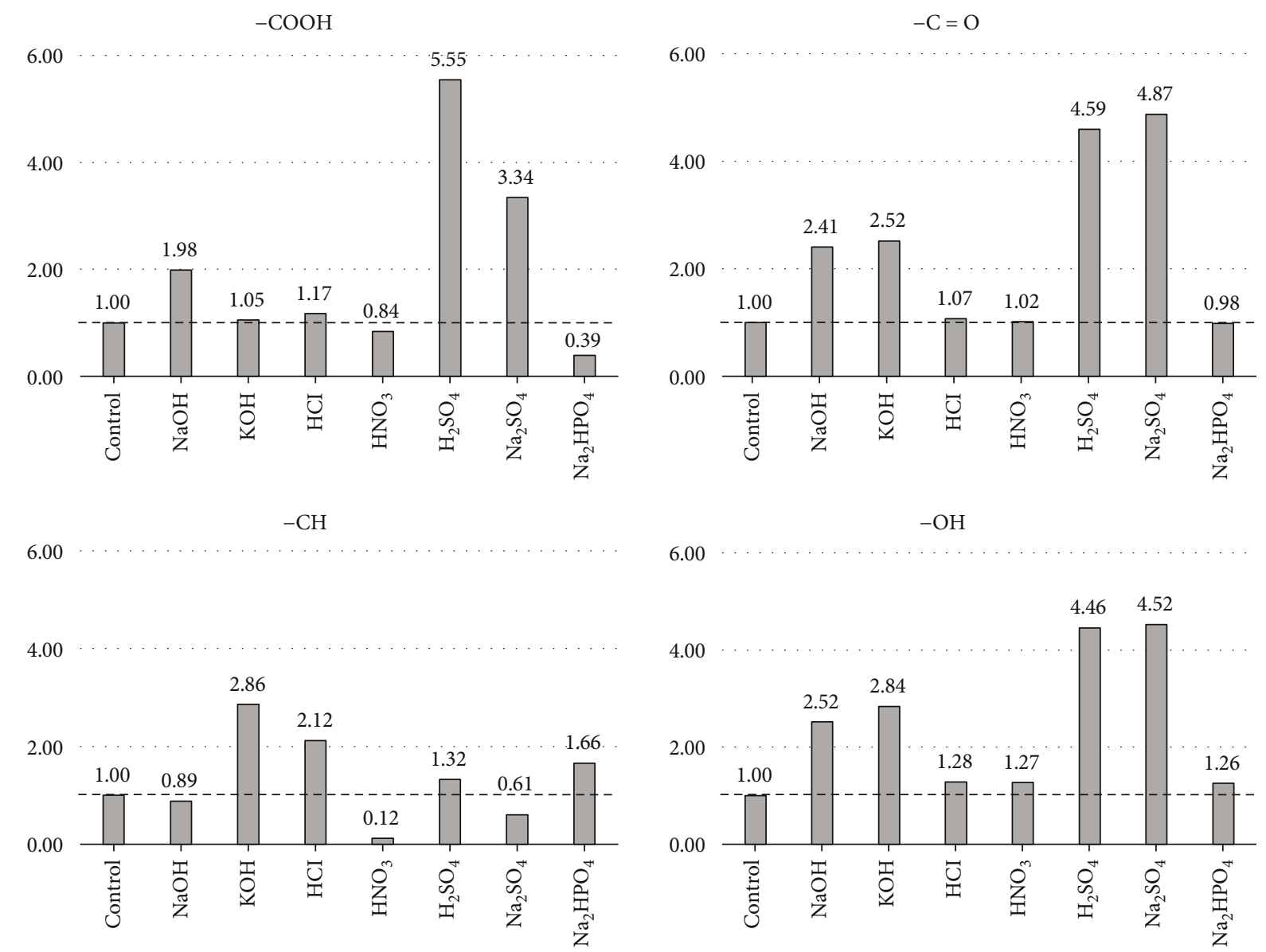

FIGURE 2: Intensity ratio of different functional groups following chemical surface treatment relative to the control (distilled water). 


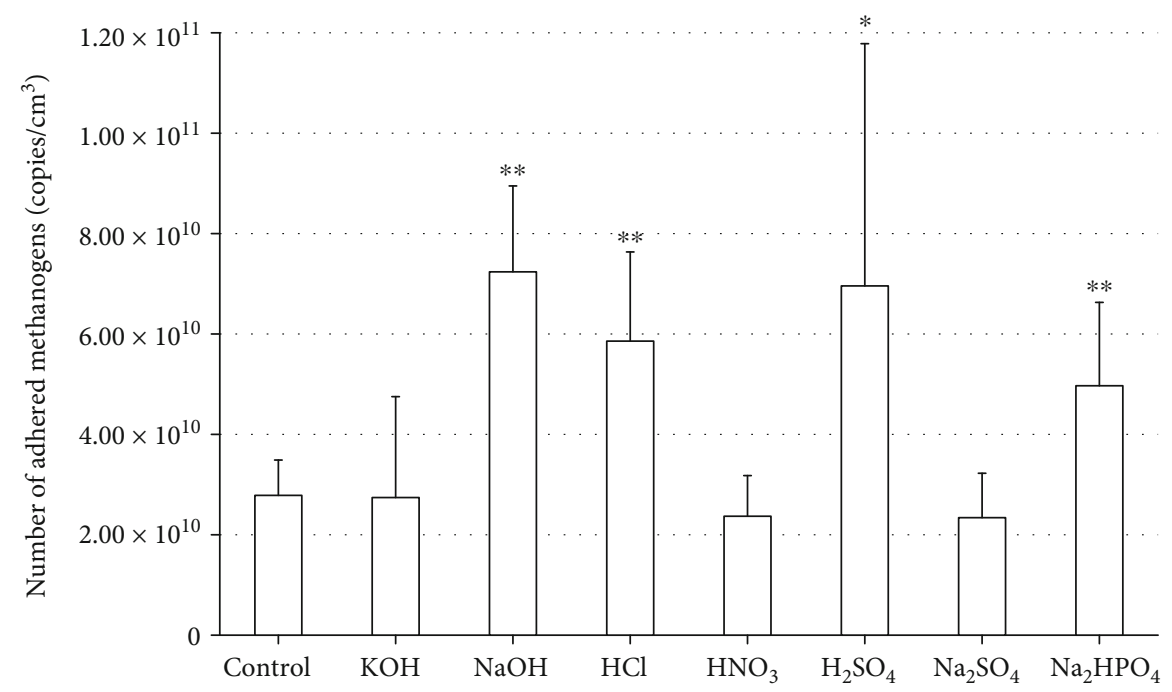

Figure 3: Abundance of $M$. thermautotrophicus strain $\Delta \mathrm{H}$ adhering to the carbon felt after 21 days of culture. Asterisks indicate that the treatment effect is significant $\left({ }^{*} p<0.05\right.$ and $\left.{ }^{* *} p<0.01\right)$ according to Student's $t$-test.

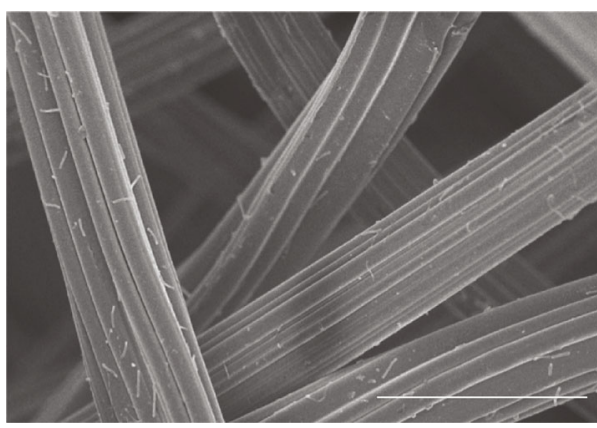

(a)

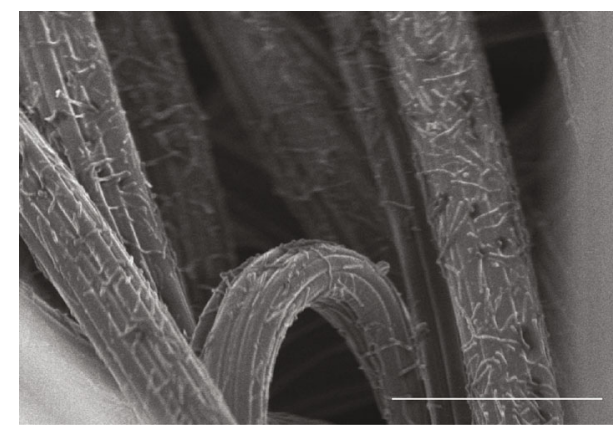

(b)

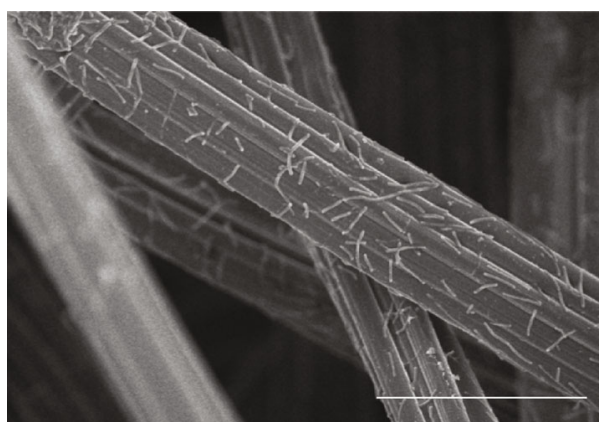

(c)

Figure 4: SEM images of carbon felt: (a) distilled water (control), (b) $\mathrm{NaOH}$, and (c) $\mathrm{HCl}$ treated. Scale bar $=30 \mu \mathrm{m}$.

3.4. Relationship between the Surface Properties of the Carrier and Adhesion of Methanogenic Archaea. As the surface hydrophobicity of the carrier is thought to strongly influence the adhesion of methanogens, the relationship between the contact angle of each treated carrier and the quantity of methanogen adhesion was evaluated (Figure 5). A decrease in contact angle was recorded for all treated carrier surfaces tested in this study relative to the control; however, no correlation was noted between the surface contact angle and adhering quantity of methanogens $\left(R^{2}=0.1688\right)$.
Finally, the relationship between the surface functional groups of each carbon felt and adhesion of methanogenic archaea was examined. The amount of the four functional groups $(-\mathrm{COOH},-\mathrm{C}=\mathrm{O},-\mathrm{CH}$, and $-\mathrm{OH}$ ) changed across the seven types of chemical treatment applied in this study. A one-on-one relationship between the abundance of each functional group and adhesion of methanogens was examined; however, no significant correlation was noted for any functional group. Considering that multiple functional groups interact with each other to influence overall surface 


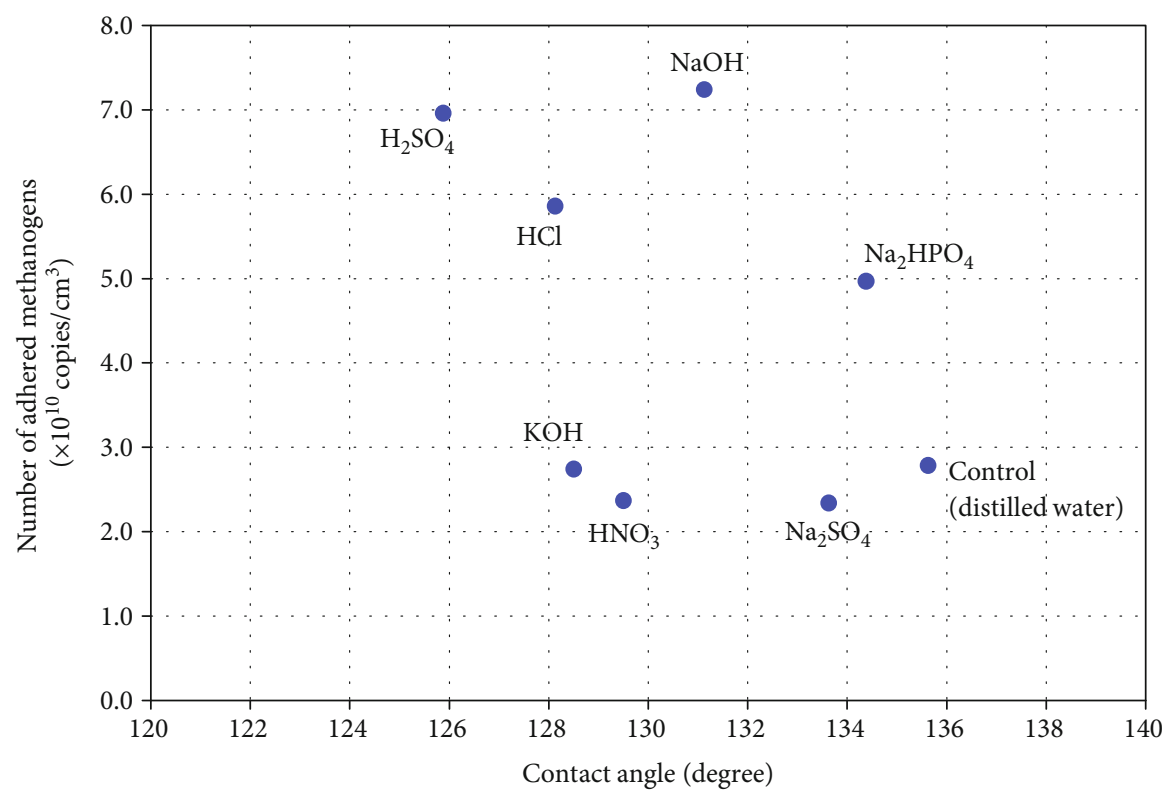

FIGURE 5: Number of adhered methanogens vs. water contact angle of carbon felts.

affinity for methanogens, the relationship between the quantity of methanogens and the $-\mathrm{COOH}$ and $-\mathrm{OH}$ groups was investigated (Figure 6). With four treated carriers $(\mathrm{NaOH}$, $\mathrm{H}_{2} \mathrm{SO}_{4}, \mathrm{HCl}$, and $\mathrm{NaH}_{2} \mathrm{PO}_{4}$ ), which had a lot of methanogens attached, the $-\mathrm{COOH}$ and $-\mathrm{OH}$ groups showed stronger correlation $\left(R^{2}=0.9607\right)$. In contrast, with the $\mathrm{KOH}$ - and $\mathrm{Na}_{2} \mathrm{SO}_{4}$-treated carbon felts, in which the quantity of adhesion did not increase, the correlation of the $-\mathrm{COOH}$ and $-\mathrm{OH}$ groups was low. These findings suggest that the affinity of the carrier for methanogens was augmented when its surface $-\mathrm{COOH}$ and $-\mathrm{OH}$ groups were modified in a wellbalanced manner. From the degree of the approximate curve and comparison to the standard of functional group distribution of the control, it was thought that it was desirable for a functional group to be distributed in the ratio of $\mathrm{COOH}:-\mathrm{OH}=1: 0.65$.

\section{Discussion}

This study demonstrates that chemical surface treatments of carbon felt material could either increase or decrease the adhesion of the $M$. thermautotrophicus strain $\Delta \mathrm{H}$. A previous study showed that acid treatment of the carbon brush electrode altered the surface area of the electrode and increased the adhesion of microorganisms [22]. SEM revealed no apparent roughness on the carbon felt surface following any of the chemical treatments conducted in this study (data not shown). Therefore, we believe that no significant changes to the physical appearance of the carrier surface occurred in these experiments.

In general, the cell surface of methanogenic archaea is hydrophobic compared with that of bacteria [23], which makes these cells likely to adhere to more hydrophobic surfaces $[24,25]$. Previously, when Verrier compared the quantity of initial adhesion of methanogenic archaea using

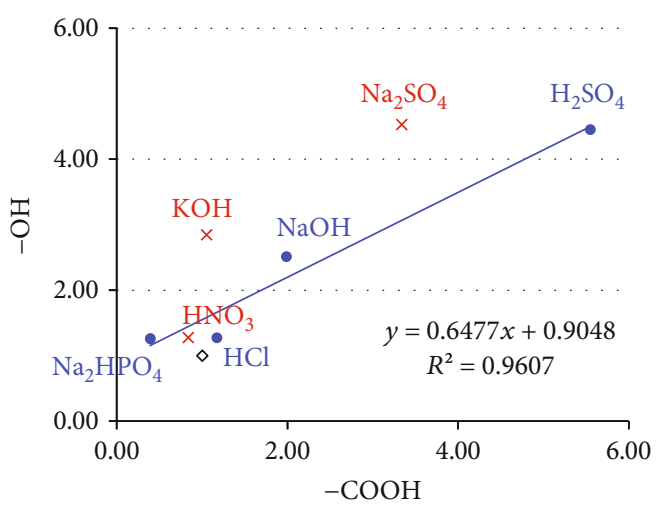

Figure 6: Correlation between $-\mathrm{OH}$ and $-\mathrm{COOH}$ functional groups on the surface of the carrier (treated with $\mathrm{NaOH}, \mathrm{HCl}$, $\mathrm{H}_{2} \mathrm{SO}_{4}$, or $\mathrm{Na}_{2} \mathrm{HPO}_{4}$ ) wherein quantity of adhesion of methanogen improved. The correlation was determined by linear regression: $y=m x$, where $y=$ relative amount of $-\mathrm{OH}$ and $x=$ relative amount of -COOH; $r^{2}$ is the coefficient of determination.

the polymers with different contact angles, Methanospirillum hungatei JFI attached to a hydrophilic surface (water contact angle $58-65^{\circ}$ ), whereas Methanosaeta concilii attached to a hydrophobic polymer (contact angle 90$102^{\circ}$ ) willingly [3]. Therefore, it is thought that a favorable hydrophobicity condition of the carrier surface varies according to the kind of methanogen species. In this study, the treated carbon felts showed very strong hydrophobicity (water contact angle $126-134^{\circ}$ ), but M. thermautotrophicus attached to all carriers. On the other hand, the $\mathrm{KOH}$-, $\mathrm{HCl}$-, $\mathrm{HNO}_{3}{ }^{-}$, and $\mathrm{H}_{2} \mathrm{SO}_{4}$-treated carriers were significantly hydrophilized, but no correlation was observed between the carrier surface contact angle and adhesion of archaea (Figure 5). 
Though all carbon felts showed strong hydrophobicity conditions, a difference was seen in the quantity of adhesion of methanogenic archaea after chemical treatment. Therefore, there is a possibility of an interaction between physicochemical surface properties, which potentially influences the adhesion of methanogens. A quantitative comparison of functional groups on the carrier surface using FT-IR revealed that the amounts of $-\mathrm{COOH},-\mathrm{C}=\mathrm{O},-\mathrm{CH}$, and $-\mathrm{OH}$ groups changed with chemical treatments. In particular, with four treated carriers $\left(\mathrm{NaOH}, \mathrm{H}_{2} \mathrm{SO}_{4}, \mathrm{HCl}\right.$, and $\left.\mathrm{NaH}_{2} \mathrm{PO}_{4}\right)$, to which a lot of methanogens were attached, the $-\mathrm{COOH}$ and -OH groups existed at a fixed ratio in comparison with the control $\left(R^{2}=0.9607\right)$. Generally, carboxyl and phosphate groups are abundant on the surface of microorganisms, where they are believed to promote adhesion through formation of an ester bond with the carrier surface [26]. Thus, it is possible that a well-balanced modification of the $-\mathrm{COOH}$ and $-\mathrm{OH}$ groups on the carrier surface promoted a chemical bond with $M$. thermautotrophicus strain $\Delta \mathrm{H}$ and improved adhesion. On the other hand, the adhesion quantity of methanogen did not increase although the $-\mathrm{COOH}$ and - $\mathrm{OH}$ groups were distributed over the $\mathrm{HNO}_{3}$-treated carbon felt in the approximate ratio as in the four carriers above. The $\mathrm{HNO}_{3}$-treated carrier showed a decreased $-\mathrm{CH}_{3}$ group and was $1 / 10$ of that in the control, so the adhesion characteristic of methane bacteria would be clarified in greater detail by evaluating other functional groups and surface properties.

In anaerobic digestion, adhesion experiments with pure methanogenic cultures have focused on acetotrophic methanogens, because these organisms are regarded as playing a dominant role in methane production [4, 27]. Montero et al. reported that hydrogenotrophic methanogens, which were involved in active methanation during the startup phase, were replaced by acetotrophic methanogens when the reactor reached steady-state conditions [5]. Therefore, at the onset of anaerobic digestion, adhesion of hydrogenotrophic methanogens is more important than that of acetotrophic methanogens. In addition, it is thought that hydrogenotrophic methanogens have an important role in direct interspecies electron transfer (DIET) because these methanogens were the dominant species during anaerobic digestion using a conductive carrier and an electrochemical methanogenic cathode. For the effective utilization of methanogenic archaea, it is necessary to evaluate the adhesion of a wide range of methanogenic species as well as acetotrophic methanogens.

The results of the present study suggest that functional groups on the carrier surface contribute to the adhesion of methanogenic archaea. The abundance of functional groups among methanogenic archaea varies greatly because of differences in the cell wall structure among species [28]. Therefore, future studies on the adhesion mechanism of methanogenic archaea should focus on functional group distribution and chemical bonding as well as physical properties on the surface of the carrier and microorganisms. It is thought that adhesion experiments using chemical surface modifications and pure culture are effective at clarifying adhesion properties, such as in the present study. The applicability of anaerobic digestions will greatly improve by controlling the adhesion of methanogenic archaea.

\section{Conclusions}

The amount of $M$. thermautotrophicus strain $\Delta \mathrm{H}$ adhering to the carbon felt surface increased following treatment with $\mathrm{NaOH}, \mathrm{H}_{2} \mathrm{SO}_{4}, \mathrm{HCl}$, or $\mathrm{NaH}_{2} \mathrm{PO}_{4}$. Chemical treatment changed the hydrophobicity of the carbon felt surface, but no correlation was observed between the carrier surface contact angle and adhesion of archaea. The number of adhering $M$. thermautotrophicus was greater on a carbon felt, whose surface - $\mathrm{COOH}:-\mathrm{OH}$ ratio was $1: 0.68$. Hydrogenotrophic methanogens are known to have important roles in anaerobic digestion and electrochemistry methanation. Therefore, the performance of anaerobic digestions will improve by controlling the adhesion of hydrogenotrophic methanogen such as $M$. thermautotrophicus using chemical surface modification.

In addition, our results suggested that the functional groups of the carrier surface influenced the adhesion of methanogenic archaea. The adhesion mechanism may become clear in the future by focusing on functional group distribution and chemical bonding as well as physical characteristics.

\section{Data Availability}

The data used to support the findings of this study are available from the corresponding author upon request.

\section{Conflicts of Interest}

The authors declare that there is no conflict of interest regarding the publication of this paper.

\section{Acknowledgments}

This work was supported by JSPS KAKENHI (grant numbers JP17H06296 and JP19J13004). The authors would like to thank K. Ito for assistance with SEM observation.

\section{References}

[1] R. E. Speece, "Anaerobic biotechnology for industrial wastewater treatment," Environmental Science \& Technology, vol. 17, no. 9, pp. 416-427, 1983.

[2] F. Habouzit, G. Gévaudan, J. Hamelin, J. P. Steyer, and $\mathrm{N}$. Bernet, "Influence of support material properties on the potential selection of Archaea during initial adhesion of a methanogenic consortium," Bioresource Technology, vol. 102, no. 5, pp. 4054-4060, 2011.

[3] D. Verrier, B. Mortier, and G. Albagnac, "Initial adhesion of methanogenic bacteria to polymers," Biotechnology Letters, vol. 9, no. 10, pp. 735-740, 1987.

[4] T. Nomura, "Control of microbial adhesion using fine particle technology," Advanced Powder Technology, vol. 2, no. 5, pp. 532-537, 2012.

[5] B. Montero, J. L. Garcia-Morales, D. Sales, and R. Solera, "Evolution of microorganisms in thermophilic-dry anaerobic digestion," Bioresource Technology, vol. 99, no. 8, pp. 32333243, 2008.

[6] M. Morita, N. S. Malvankar, A. E. Franks et al., "Potential for direct interspecies electron transfer in methanogenic wastewater digester aggregates," MBio, vol. 2, no. 4, pp. 1-8, 2011. 
[7] S. Chen, A. E. Rotaru, F. Liu et al., "Carbon cloth stimulates direct interspecies electron transfer in syntrophic co-cultures," Bioresource Technology, vol. 173, no. 1, pp. 82-86, 2014.

[8] Z. Zhao, Y. Zhang, T. L. Woodard, K. P. Nevin, and D. R. Lovley, "Enhancing syntrophic metabolism in up-flow anaerobic sludge blanket reactors with conductive carbon materials," Bioresource Technology, vol. 191, no. 1, pp. 140-145, 2015.

[9] S. Kato, K. Hashimoto, and K. Watanabe, "Methanogenesis facilitated by electric syntrophy via (semi) conductive ironoxide minerals," Environmental Microbiology, vol. 14, no. 7, pp. 1646-1654, 2012.

[10] S. Zhou, J. Xu, G. Yang, and L. Zhuang, "Methanogenesis affected by the co-occurrence of iron (III) oxides and humic substances," FEMS Microbiology Ecology, vol. 88, no. 1, pp. 107-120, 2014.

[11] S. Cheng, D. Xing, D. F. Call, and B. E. Logan, "Direct biological conversion of electrical current into methane by electromethanogenesis," Environmental Science \& Technology, vol. 43 , no. 10 , pp. $3953-3958,2009$.

[12] Q. Fu, Y. Kuramochi, N. Fukushima, H. Maeda, K. Sato, and H. Kobayashi, "Bioelectrochemical analyses of the development of a thermophilic biocathode catalyzing electromethanogenesis," Environmental Science \& Technology, vol. 49, no. 2, pp. 1225-1232, 2015.

[13] Y. A. Gorby, S. Yanina, J. S. McLean et al., "Electrically conductive bacterial nanowires produced by Shewanella oneidensis strain MR-1 and other microorganisms," Proceedings of the National Academy of Sciences of the United States of America, vol. 103, no. 30, pp. 11358-11363, 2006.

[14] S. Kato and K. Watanabe, "Ecological and evolutionary interactions in syntrophic methanogenic consortia," Microbes and Environments, vol. 25, no. 3, pp. 145-151, 2010.

[15] H. Kobayashi, A. Nagashima, M. Kouyama et al., "High-pressure thermophilic electromethanogenic system producing methane at $5 \mathrm{MPa}, 55{ }^{\circ} \mathrm{C}$," Journal of Bioscience and Bioengineering, vol. 124, no. 3, pp. 327-332, 2017.

[16] S. Ishii, T. Kosaka, K. Hori, Y. Hotta, and K. Watanabe, "Coaggregation facilitates interspecies hydrogen transfer between Pelotomaculum thermopropionicum and Methanothermobacter thermautotrophicus," Applied and Environmental Microbiology, vol. 71, no. 12, pp. 7838-7845, 2005.

[17] R. Watanabe, C. Tada, Y. Baba, Y. Fukuda, and Y. Nakai, "Enhancing methane production during the anaerobic digestion of crude glycerol using Japanese cedar charcoal," Bioresource Technology, vol. 150, no. 1, pp. 387-392, 2013.

[18] T. Watanabe, M. Kimura, and S. Asakawa, "Dynamics of methanogenic archaeal communities based on rRNA analysis and their relation to methanogenic activity in Japanese paddy field soils," Soil Biology \& Biochemistry, vol. 39, no. 11, pp. 2877-2887, 2007.

[19] X. G. Li, K. L. Huang, S. Q. Liu, N. Tan, and L. Q. Chen, "Characteristics of graphite felt electrode electrochemically oxidized for vanadium redox battery application," Transactions of Nonferrous Metals Society of China, vol. 17, no. 1, pp. 195-199, 2007.

[20] X. W. Liu, X. F. Sun, Y. X. Huang, G. P. Sheng, S. G. Wang, and H. Q. Yu, "Carbon nanotube/chitosan nanocomposite as a biocompatible biocathode material to enhance the electricity generation of a microbial fuel cell," Energy \& Environmental Science, vol. 4, no. 4, pp. 1422-1427, 2011.
[21] X. Tang, K. Guo, H. Li, Z. Du, and J. Tian, "Electrochemical treatment of graphite to enhance electron transfer from bacteria to electrodes," Bioresource Technology, vol. 102, no. 3, pp. 3558-3560, 2011.

[22] Y. Feng, Q. Yang, X. Wang, and B. E. Logan, "Treatment of carbon fiber brush anodes for improving power generation in air- cathode microbial fuel cells," Journal of Power Sources, vol. 195, no. 7, pp. 1841-1844, 2010.

[23] D. Daffonchio, J. Thaveesri, and W. Verstraete, "Contact angle measurement and cell hydrophobicity of granular sludge from upflow anaerobic sludge bed reactors," Applied Environmental Microbiology, vol. 61, no. 10, pp. 3676-3680, 1995.

[24] Y. H. An and R. J. Friedman, "Concise review of mechanisms of bacterial adhesion to biomaterial surfaces," Journal of Biomedical Materials Research, vol. 43, no. 3, pp. 338-348, 1998.

[25] A. Chauhan and A. Ogram, "Evaluation of support matrices for immobilization of anaerobic consortia for efficient carbon cycling in waste regeneration," Biochemical and Biophysical Research Communications, vol. 327, no. 3, pp. 884-893, 2005.

[26] S. J. Parikh, F. N. Mukome, and X. Zhang, "ATR-FTIR spectroscopic evidence for biomolecular phosphorus and carboxyl groups facilitating bacterial adhesion to iron oxides," Colloids and Surfaces B: Biointerfaces, vol. 119, no. 1, pp. 38-46, 2014.

[27] V. Nguyen, E. Karunakaran, G. Collins, and C. A. Biggs, "Physicochemical analysis of initial adhesion and biofilm formation of Methanosarcina barkeri on polymer support material," Colloids and Surfaces B: Biointerfaces, vol. 143, no. 1, pp. 518-525, 2016.

[28] S. V. Albers and B. H. Meyer, "The archaeal cell envelope," Nature Reviews Microbiology, vol. 9, no. 6, pp. 414-426, 2011. 